\title{
A case of cytomegalovirus-negative Ménétrier's disease with eosinophilia in a child
}

Keun Hyung Son, $M D^{1}$, Jeong Ja Kwak, MD², Jae Ock Park, MD'

Departments of ${ }^{1}$ Pediatrics and ${ }^{2}$ Pathology, Soonchunhyang University Bucheon Hospital, Soonchunhyang University College of Medicine, Bucheon, Korea
Received: 4 April 2011, Revised: 6 October 2011

Accepted: 16 April 2012

Corresponding author: Jae Ock Park, MD

Department of Pediatrics, Soonchunhyang University Bucheon Hospital, Soonchunhyang University College of Medicine, 170 Jomaru-ro, Wonmi-gu, Bucheon 420-767, Korea

Tel: +82-32-621-5403, Fax: +82-32-621-5662

E-mail: jop50@schmc.ac.kr

Copyright (C) 2012 by The Korean Pediatric Society
Ménétrier's disease is a rare form of acquired gastropathy characterized by giant rugal folds in the stomach and protein-losing gastropathy. Children with Ménétrier's disease tend to follow a benign self-limited course with symptoms typically completely resolving within 2 to 10 weeks in contrast to the chronic course in adults. A 9-year-old girl presented with a history of gradually worsening abdominal distension, increasing body weight, and abdominal pain for 2 weeks. Physical examination on admission indicated periorbital swelling, pitting edema in both the legs, and abdominal distension with mild diffuse tenderness and shifting dullness. Laboratory tests on admission showed hypoalbuminemia, hypoproteinemia, and peripheral eosinophilia. The test result for anticytomegalovirus immunoglobulin $M$ was negative. Increased fecal alpha 1 anti-trypsin excretion was observed. Radiological findings showed massive ascites and pleural effusion in both the lungs. On gastroscopy, large gastric folds, erythema, erosion, and exudation were noted in the body and fundus of the stomach. Microscopic findings showed infiltration of eosinophils and neutrophils in the gastric mucosa. Her symptoms improved with conservative treatment from day 7 of hospitalization and resolved completely.

Key words: Ménétrier's disease, Gastritis hypertrophic, Hypoalbuminemia, Protein-losing enteropathies, Eosinophilia, Cytomegalovirus

This is an open-access article distributed under the terms of the Creative Commons Attribution Non-Commercial License (http://creativecommons.org/licenses/by $\mathrm{nc} / 3.0 /$ ) which permits unrestricted non-commercial use, distribution, and reproduction in any medium, provided the original work is properly cited.

\section{Introduction}

Ménétrier's disease is a rare form of acquired gastropathy characterized by giant rugal folds in the stomach and protein-losing gastropathy ${ }^{1)}$. Although it is a chronic progressive disorder in adults, Ménétrier's disease in children, rarely needs aggressive treatment and resolves spontaneously within 2 to 10 weeks with supportive measures only. Many cases of pediatric Ménétrier's disease associated with cytomegalovirus (CMV) infection have been reported ${ }^{2}$. Clinical findings among children include nausea, vomiting, abdominal pain, peripheral edema, ascites, and pleural effusion. Gastroduodenal endoscopy is useful for confirming the diagnosis of Ménétrier's disease by direct observation and for obtaining biopsy material and exclude other conditions that may mimic this disorder".

To our knowledge, only a limited number of Ménétrier's disease cases have been reported in children since the first case reported in $1888^{1)}$. We present a case of Ménétrier's disease in a 9-yearold girl with abdominal pain, ascites, and pleural effusion. CMV 
infection was not associated and showed peripheral and histological eosinophila. We also review the literature on Ménétrier's disease in children.

\section{Case report}

A 9-year-old girl presented with a history of gradually worsening abdominal distension, decreased urine output, and abdominal pain for 2 weeks. Two weeks prior to admission, she complained of nausea, vomiting, and abdominal pain without diarrhea several hours after eating bread. She had no signs of infection such as fever, rash, or sore throat. On admission, she was afebrile and had normal vital signs. Her weight was $32.2 \mathrm{~kg}$ (50th to 75 th percentile), and height was $140 \mathrm{~cm}$ (75th to 90th percentile). She had a history of allergic rhinitis. A physical examination revealed periorbital swelling, pitting edema on both legs, and abdominal distension with mild diffuse tenderness and shifting dullness. Laboratory tests on admission showed hemoglobin level, $15.4 \mathrm{~g} / \mathrm{dL}$; hematocrit, 43\%; peripheral leukocyte, $13.390 / \mu \mathrm{L}$ with an eosinophil count of $840 / \mu \mathrm{L}(6.3 \%)$; serum total protein, $2.3 \mathrm{~g} / \mathrm{dL}$; albumin, $1.3 \mathrm{~g} / \mathrm{dL}$; calcium, $7.3 \mathrm{mg} /$ $\mathrm{dL}$; erythrocyte sedimentation rate, $2 \mathrm{~mm} / \mathrm{hr}$; and C-reactive protein, $0.56 \mathrm{mg} / \mathrm{dL}$. A urinalysis was normal without proteinuria. The multiple allergen simultaneous test showed positive responses to mites (class 2) and Acarus siro (class 3), with elevation of the total immunoglobulin (Ig) E value (>200 IU/mL). Anti-CMV IgM was negative. Chest and abdominal radiographs displayed pleural effusion on both sides. Abdominal ultrasonography revealed pleural effusion and massive ascites. Computed tomography (CT) of the abdomen confirmed marked thickening of the small intestinal wall. A pleural fluid analysis revealed lymphocytes, $25 \%$; polymorphonuclear neutrophils, 7\%; eosinophils, $0 \%$; protein, $152 \mathrm{mg} /$ dL; glucose, $116 \mathrm{mg} / \mathrm{dL}$; and adenosine deaminase, $2 \mathrm{IU} / \mathrm{L}$. An abdominal paracentesis was not performed. Alpha 1 anti-trypsin excretion in the stool was elevated to $1,204 \mathrm{mg} / \mathrm{dL}$ (normal, $\leq 54 \mathrm{mg}$ / dL). A gastroscopic examination revealed large swollen gastric folds, erythema, erosion, and exudation in the body and fundus, although the antrum was normal (Fig. 1). A Campylobacter-like organism test was negative. Histological findings of the gastric mucosa showed moderate infiltration of eosinophils (20 to 38 per high power field) and neutrophils in the lamina propria, mucosal edema, and dilatation of the capillaries and lymphatics (Fig. 2). A cell with intranuclear and intracytoplasmic inclusions, characteristic of CMV infection, was not seen. Immunohistochemistry for CMV revealed negative finding. Microscopic findings of the duodenal mucosa revealed mild infiltration of lymphocytes and histiocytes with few eosinophils. The patient's symptoms of abdominal distension, pitting edema, and decreased urine output began to improve from the day 7 of hospitalization with conservative treatments such as fluid restriction, diuretics, albumin infusion, and avoidance of milk and bread. Peripheral eosinophils rose to $25.4 \%(1,520 / \mathrm{uL})$ on the day 11 after

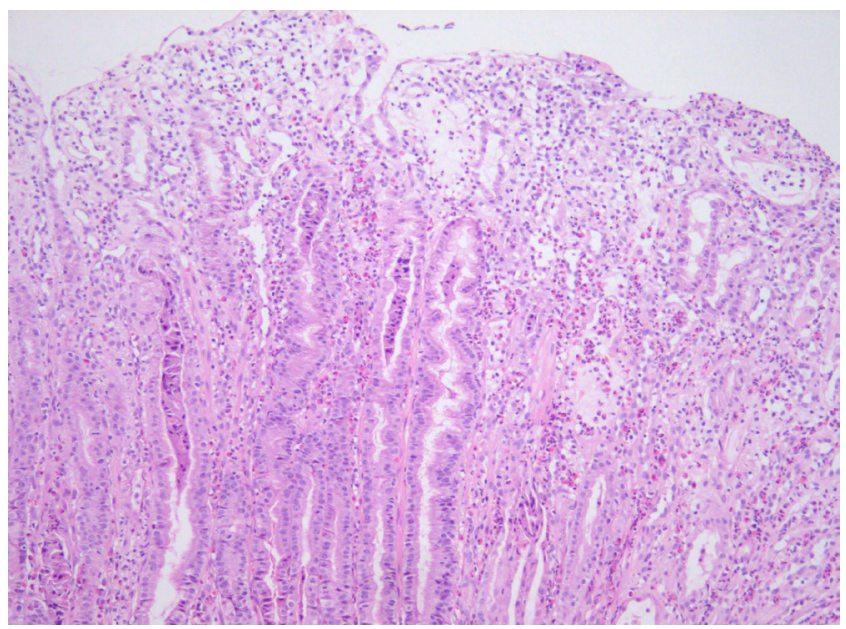

Fig. 2. Microscopic examination of the gastric mucosa showed moderate infiltration of eosinophils and neutrophils, mucosal edema, and dilatation of capillaries and lymphatics $(H \& E, \times 100)$.

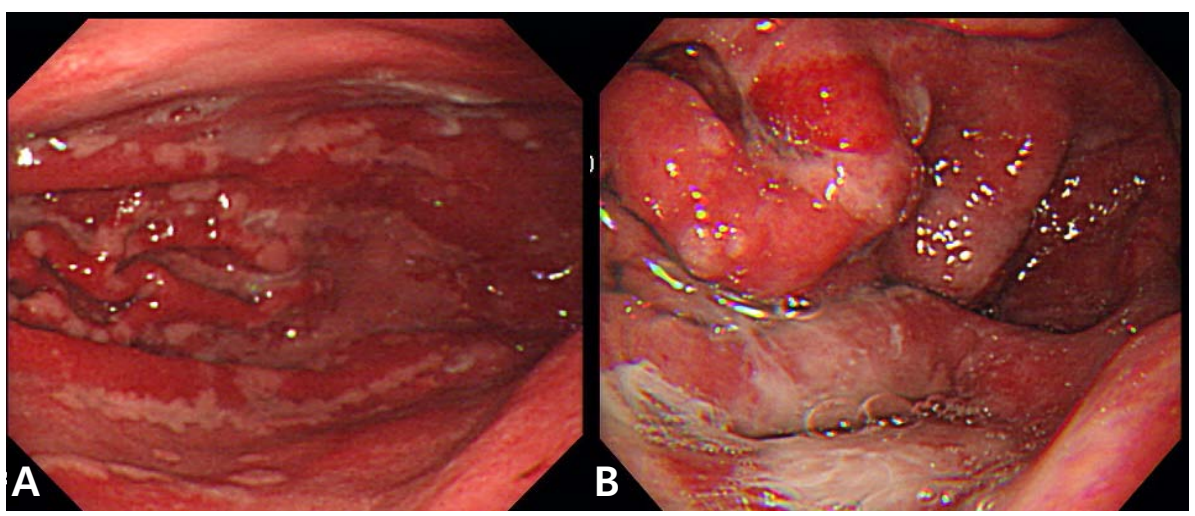

Fig. 1. On gastroscopy, large and edematous gastric folds, erythema, erosion, and exudation were observed in the $(A)$ body and $(B)$ fundus of the stomach. 
admission. Total protein and albumin levels rose to $4.3 \mathrm{~g} / \mathrm{dL}$ and $3 \mathrm{~g} /$ $\mathrm{dL}$, respectively, and her weight reduced from 32.3 to $27.3 \mathrm{~kg}$ on the day of discharge, 17 days after admission.

\section{Discussion}

Ménétrier's disease is a rare acquired disorder of the stomach characterized by giant hyperplastic folds, excess mucus secretion, decreased acid secretion (hypochlorhydria), and hypoproteinemia due to selective loss of serum proteins across the gastric mucosa ${ }^{3}$. Ménétrier's disease usually presents with an insidious onset and a progressive, chronic, and unremitting clinical course in adults ${ }^{4,5}$. However, the disorder is characterized by abrupt onset and spontaneous resolution within 2 to 10 weeks without any special treatment in children ${ }^{2)}$.

Ménétrier's disease is associated with $\mathrm{CMV}^{1,2,6,7)}$, Helicobacter pylori $^{8,9)}$, herpes simplex virus ${ }^{10)}$ and Mycoplasma pneumoniae ${ }^{11)}$ infections. The previous study has described that $\mathrm{CMV}$ infection was associated in $70 \%$ of children with Ménétrier's disease ${ }^{2)}$. Two Korean cases reported in 2001 and 2004 were also associated with CMV infection in preschool-age boys ${ }^{7,12)}$. The presence of CMV infection can be identified by serology or immunohistochemisty. H. pylori is thought to have a role in Ménétrier's disease in adults but its role in pediatric Ménétrier's disease has not yet been established. Recently, Tokuhara et al. ${ }^{13)}$ reported pediatric Ménétrier's disease that had coinfection with CMV and $H$. pylori. They concluded that this case of pediatric Ménétrier's disease was secondary to $H$. pylori infection rather than CMV infection, because the clinical, biochemical resolution of the disease occurred after the eradication therapy against H. pylori.

Its cause is unknown, but the possibilities include chemical irritants, toxins, dietary factors, neuro-emotional, endocrinological, or immunological abnormalities, allergic processes, or autoimmune disorders ${ }^{14,15)}$. Recent research implicates overproduction of transforming growth factor-alpha (TGF- $\alpha$ ) with increased signaling of the epidermal growth factor receptor (EGFR) in the pathogenesis of this condition ${ }^{16}$. TGF- $\alpha$ is one of six mammalian ligands that bind to the EGFR. Activation of the EGFR, a transmembrane receptor with tyrosine kinase activity, triggers a cascade of downstream intracellular signaling pathways that leads to expansion of the proliferative compartment within the isthmus of the gastric mucosa cells. As a result, production of gastric mucus increases and production of gastric acid decreases ${ }^{17)}$.

The most accepted criteria for diagnosis of Ménétrier's disease include giant folds, particularly in the fundus and body of the stomach (generally spares the antrum), hypoalbuminemia (protein- losing gastroenteropathy), and histological features of foveolar hyperplasia, cystic dilatation of pits, and reduced numbers of parietal and chief cells ${ }^{17}$. Some cases of Ménétrier's disease show infiltration of eosinophils into the gastric mucosa ${ }^{1,18)}$. Schroder ${ }^{15)}$ noted that the association between eosinophilia and Ménétrier's disease is a hypersensitivity mechanism. Diagnosis of Ménétrier's disease is difficult to establish with routine endoscopic superficial mucosal pinch biopsies; deeper snare or full-thickness biopsies of the gastric mucosa are more informative, because the gastric rugal folds in patients with Ménétrier's disease are edematous and large ${ }^{19)}$. The histological finding of this child revealed moderate eosinophilic infiltration (20 to 38 per high power field) and no evidence of foveolar hyperplasia or cystic dilatation of the pits. It was very confusing to diagnose this patient as Ménétrier's disease with such histoloic findings. It was due to the result not performing the fullthickness biopsy. With routine endoscopic superficial mucosal pinch biopsies, Ménétrier's disease when shows peripheral eosinophilia or mucosal eosinophilic infiltration may be confused with eosinophilic gastroenteritis.

Image examinations such as ultrasonography, CT, and a barium study show the characteristic hypertrophic gastric folds and edema of the proximal small intestine ${ }^{20,21)}$. In our case, marked thickening of the small intestine wall was revealed on CT.

The differential diagnoses of enlarged gastric rugal folds detected radiographically include lymphoma, eosinophilic gastropathy, multiple polyps, gastric varices, Zollinger-Ellison syndrome, and lymphangiectasia ${ }^{22)}$. The two most important diseases with large gastric folds that should be distinguished from Ménétrier's disease are gastric lymphoma and eosinophilic gastroenteritis. Primary gastric lymphoma is a rare entity in children. It is primarily a disease of the elderly, with a peak incidence in the seventh decade ${ }^{23}$. Eosinophilic gastroenteritis is an uncommon benign disorder characterized by eosinophilic infiltration of the stomach, particularly in the antrum, and/or small bowel wall ${ }^{24}$. The clinical course of eosinophilic gastroenteritis is highly variable ${ }^{25)}$. Treatment with steroids is the mainstay for managing eosinophilic gastroenteritis ${ }^{26}$. The definitive method to distinguish Ménétrier's disease from primary stomach lesions is an adequate biopsy ${ }^{27)}$.

The mechanism of protein leakage from gastric mucosa is known from ultrastructural changes in the gastric mucosa. Oderda et al. ${ }^{28)}$ described that electron microscopy showed a marked increase in the width of the tight junctions in patients with Ménétrier's disease. Other causes of protein-losing gastroenteropathy include eosinophilic gastroenteritis, gastric lymphoma, celiac disease, hypertrophic gastropathy in association with $H$. pylori infection, and Crohn's disease. 
Because most cases of childhood Ménétrier's disease are selflimiting, the treatment is largely supportive such as a high-protein diet, fluid restriction, diuretics, and albumin infusion. Ganciclovir therapy may be attempted in CMV-positive cases that fail to remit spontaneously in 4 to 6 weeks ${ }^{6}$. Adult patients are often treated with $\mathrm{H} 2$ receptor blockers, proton pump inhibitors, and anticholinergic medications ${ }^{29)}$. Eradicating an $H$. pylori infection may be beneficial and should be considered ${ }^{8}$. Partial or total gastrectomy is recommended for patients with persistent and sufficiently distressing symptoms such as massive bleeding, refractory protein loss, or obstruction ${ }^{29,30}$. Recently, therapies targeting the increased EGFR signal are promising, including somatostatin analogues and monoclonal antibodies (e.g., cetuximab) ${ }^{30,31)}$.

We recommend a clinicohistopathological analysis with successful full-thickness gastric mucosal biopsy to approach suspected Ménétrier's disease.

\section{References}

1. Chouraqui JP, Roy CC, Brochu P, Gregoire H, Morin CL, Weber AM. Menetrier's disease in children: report of a patient and review of sixteen other cases. Gastroenterology 1981;80(5 pt 1):1042-7.

2. Occena RO, Taylor SF, Robinson CC, Sokol RJ. Association of cytomegalovirus with Menetrier's disease in childhood: report of two new cases with a review of literature. J Pediatr Gastroenterol Nutr 1993;17:217-24.

3. Wolfsen HC, Carpenter HA, Talley NJ. Menetrier's disease: a form of hypertrophic gastropathy or gastritis? Gastroenterology 1993;104:1310-9.

4. Scharschmidt BF. The natural history of hypertrophic gastrophy (Menetrier's disease). Report of a case with 16 year follow-up and review of 120 cases from the literature. Am J Med 1977;63:644-52.

5. Lim YJ, Rhee PL, Kim YH, Lee SJ, Lee MS, Kang TW, et al. Clinical features of Menetrier's disease in Korea. Korean J Gastrointest Endosc 2000;21:909-16

6. Hoffer V, Finkelstein Y, Balter J, Feinmesser M, Garty BZ. Ganciclovir treatment in Menrtrier's disease. Acta Paediatr 2003;92:983-5.

7. Cho JR, Kang SK, Kim YH, Choe YH. A case of Menetrier's disease associated with cytomegalovirus infection. J Korean Pediatr Soc 2001;44: 1197-200.

8. Kawasaki M, Hizawa K, Aoyagi K, Nakamura S, Fujishima M. Menetrier's disease associated with Helicobacter pylori infection: resolution of enlarged gastric folds and hypoproteinemia after antibacterial treatment. Am J Gastroenterol 1997;92:1909-12.

9. Yamada M, Sumazaki R, Adachi H, Ahmed T, Matsubara T, Hori T, et al. Resolution of protein-losing hypertrophic gastropathy by eradication of Helicobacter pylori. Eur J Pediatr 1997;156:182-5.

10. Jun DW, Kim DH, Kim SH, Song MH, Lee HH, Kim SH, et al. Menetrier's disease associated with herpes infection: response to treatment with acyclovir. Gastrointest Endosc 2007;65:1092-5.

11. Ben Amitai D, Zahavi I, Dinari G, Garty BZ. Transient protein-losing hypertrophic gastropathy associated with Mycoplasma pneumoniae infection in childhood. J Pediatr Gastroenterol Nutr 1992;14:237-9.
12. Choi WJ, Lee BY, Lee HJ, Oh HK, Hwang JB. Cytomegalovirus-induced childhood menetrier's disease with peripheral eosinophilia. Korean J Pediatr Gastroenterol Nutr 2004;7:87-91.

13. Tokuhara D, Okano Y, Asou K, Tamamori A, Yamano T. Cytomegalovirus and Helicobacter pylori co-infection in a child with Ménétrier disease. Eur J Pediatr 2007;166:63-5.

14. Fieber SS. Hypertrophic gastritis; report of two cases and analysis of fifty pathologically verified cases from the literature. Gastroenterology 1955; 28:39-69.

15. Schroder JS. Protein-losing gastroenteropathy: case report of Menetrier's disease and suggested etiology. South Med J 1961;54:249-52.

16. Barnard JA, Beauchamp RD, Russell WE, Dubois RN, Coffey RJ. Epidermal growth factor-related peptides and their relevance to gastrointestinal pathophysiology. Gastroenterology 1995;108:564-80.

17. Toubia N, Schubert ML. Menetrier's disease. Curr Treat Options Gastroenterol 2008;11:103-8.

18. Morinville V, Bernard C, Forget $S$. Foveolar hyperplasia secondary to cow's milk protein hypersensitivity presenting with clinical features of pyloric stenosis. J Pediatr Surg 2004;39:E29-31.

19. Coffey RJ, Washington MK, Corless CL, Heinrich MC. Menetrier disease and gastrointestinal stromal tumors: hyperproliferative disorders of the stomach. J Clin Invest 2007;117:70-80.

20. Takaya J, Kawamura Y, Kino M, Kawashima Y, Yamamoto A, Kobayashi Y. Menetrier's disease evaluated serially by abdominal ultrasonography. Pediatr Radiol 1997;27:178-80.

21. Sandberg DH. Hypertrophic gastropathy (Menetrier's disease) in childhood. J Pediatr 1971;78:866-8.

22. Baker A, Volberg F, Sumner T, Moran R. Childhood Menetrier's disease: four new cases and discussion of the literature. Gastrointest Radiol 1986; 11:131-4.

23. Cogliatti SB, Schmid U, Schumacher U, Eckert F, Hansmann ML, Hedderich J, et al. Primary B-cell gastric lymphoma: a clinicopathological study of 145 patients. Gastroenterology 1991;101:1159-70.

24. Edelman MJ, March TL. Eosinophilic gastroenteritis. Am J Roentgenol Radium Ther Nucl Med 1964;91:773-8.

25. Siaw EK, Sayed K, Jackson RJ. Eosinophilic gastroenteritis presenting as acute gastric perforation. J Pediatr Gastroenterol Nutr 2006;43:691-4.

26. Talley NJ, Shorter RG, Phillips SF, Zinsmeister AR. Eosinophilic gastroenteritis: a clinicopathological study of patients with disease of the mucosa, muscle layer, and subserosal tissues. Gut 1990;31:54-8.

27. Nelson RS, Lanza FL. The endoscopic diagnosis of gastric lymphoma. Gross characteristics and histology. Gastrointest Endosc 1974;21:66-8.

28. Oderda G, Cinti S, Cangiotti AM, Forni M, Ansaldi N. Increased tight junction width in two children with Menetrier's disease. J Pediatr Gastroenterol Nutr 1990;11:123-7.

29. Kraut JR, Powell R, Hruby MA, Lloyd-Still JD. Menetrier's disease in childhood: report of two cases and a review of the literature. J Pediatr Surg 1981;16:707-11.

30. Burdick JS, Chung E, Tanner G, Sun M, Paciga JE, Cheng JQ, et al. Treatment of Menetrier's disease with a monoclonal antibody against the epidermal growth factor receptor. N Engl J Med 2000;343:1697-701.

31. Rothenberg M, Pai R, Stuart K. Successful use of octreotide to treat Menetrier's disease: a rare cause of abdominal pain, weight loss, edema, and hypoalbuminemia. Dig Dis Sci 2009;54:1403-7. 